\title{
Foetal growth and duration of gestation relative to water chlorination
}

\author{
J J K Jaakkola, P Magnus, A Skrondal, B-F Hwang, G Becher, E Dybing
}

\begin{abstract}
Objective-To assess the effect of exposure to chlorination byproducts during pregnancy on foetal growth and duration of pregnancy.

Methods-A population based study was conducted of 137145 Norwegian children born alive in 1993-5. Information was obtained from the Norwegian medical birth registry, waterwork registry, and social science data service. The outcomes of interest were birth weight, low birth weight $(<2500 \mathrm{~g})$, small for gestational age, and preterm delivery (gestational age $<37$ weeks). The exposure assessment was based on quality of drinking water in the municipality where the mother lived during pregnancy. Municipal exposure was calculated with information on chlorination and the amount of natural organic matter in raw water measured as colour in mg precipitate/1. The main exposure category was high colour and chlorination, which was contrasted with the reference category of low colour and no chlorination. Results-In logistic regression analysis adjusting for confounding, the risks of low birth weight (odds ratio (OR) $0.97,95 \%$ confidence interval (95\% CI) 0.89 to 1.06$)$ and small for gestational age (OR 1.00, $95 \%$ CI 0.91 to 1.10 ) were not related to exposure. Contrary to the hypothesis, the risk of preterm delivery was slightly lower among the exposed than the reference category (OR $0.91,95 \%$ CI 0.84 to 0.99 ). The risks of the studied outcomes were similar in newborn infants exposed to high colour drinking water without chlorination and chlorinated drinking water with low colour compared with the reference category.
\end{abstract}

Conclusions-The present study did not provide evidence that prenatal exposure to chlorination byproducts at the relatively low concentrations encountered in Norwegian drinking water increases the risk of the studied outcomes.

(Occup Environ Med 2001;58:437-442)

Keywords: water chlorination; foetal growth; gestational age

epartment of

Medicine

E Dybing

Norwegian Institute for Water Research, Oslo, Norway

G Becher

Correspondence to: Professor J J K Jaakkola jouni.jaakkola@nhv.se

Accepted 14 March 2001

Chlorination is the oldest and most widely used method of water disinfection, and the practice of chlorination has had a tremendous impact in reducing water borne infections. It has been known since the 1970 s that chlorination of raw water containing natural organic matter produces organochlorine byproductssuch as chloroform-several of which are experimental carcinogens. ${ }^{12}$ Epidemiological studies have provided increasing evidence of carcinogenic effects of chlorinated water. ${ }^{2}{ }^{3}$ The main cancer sites have been the bladder, colon, and kidney. ${ }^{34}$ Reproductive outcomes have received less attention. ${ }^{5-14}$ Six previous studies assessed the effect of chlorination byproducts on the risk of low birth weight and preterm delivery, ${ }^{5} 78101114$ and three studied the effect on the risk of being small for gestational age..$^{5^{11}}$ Nieuwenhuijsen et $a l^{15}$ concluded in their recent review that toxicological and epidemiological evidence point towards an association between trihalomethanes, as an indicator of total disinfection byproduct load, and low birth weight, although the evidence is not conclusive. They found no evidence for an association between trihalomethanes and preterm delivery.

We conducted a registry based study in Norway to assess measures of foetal growth and preterm delivery relative to the content of natural organic matter in water and to chlorination in municipal waterworks in the mother's place of residence, applying a similar approach as in our recent study of birth defects as outcomes of interest. ${ }^{13}$

\section{Methods}

STUDY POPULATION

The source population comprised all 181361 newborn infants registered by the Norwegian birth registry 1993-5. This registry has collected complete information on practically all the births in Norway and it maintains careful quality control procedures. ${ }^{16}$ We applied the following exclusion criteria: (a) no information on chlorination or natural organic matter content of water from any of the municipal waterworks at the mother's place of residence (40 284 newborn infants excluded); (b) one or more congenital birth defects (2608 excluded); and (c) no information on birth weight in the birth registry (1324 excluded). The study population comprised 137145 live newborn infants. Gestational age was available for 123 $747(90.2 \%$ of the study population).

HEALTH OUTCOMES

The primary health outcomes were foetal growth and preterm delivery. We obtained information on birth weight, gestational age, and some potential confounders from The

Norwegian medical birth registry, which is week of life, after examination of the child by a physician, most often a paediatrician. The gestational age is assessed by ultrasound examination on the 12-16th gestational week in most of the pregnancies. We used three different measures of foetal growth: birth weight (g), 
Table 1 Characteristics of the study population $(n=137145)$ according to the categories of exposure, Norway, 1993-5

\begin{tabular}{|c|c|c|c|c|c|}
\hline \multirow[b]{2}{*}{ Characteristic } & \multicolumn{5}{|l|}{ Exposure category } \\
\hline & $\begin{array}{l}\text { No chlorination } \\
\text { low colour } \\
n(\%)\end{array}$ & $\begin{array}{l}\text { No chlorination } \\
\text { high colour } \\
n(\%)\end{array}$ & $\begin{array}{l}\text { Chlorination } \\
\text { low colour } \\
n(\%)\end{array}$ & $\begin{array}{l}\text { Chlorination } \\
\text { high colour } \\
n(\%)\end{array}$ & $\begin{array}{l}\text { Total } \\
n(\%)\end{array}$ \\
\hline Total & $19480(100)$ & $11836(100)$ & $34063(100)$ & $71766(100)$ & $137145(100)$ \\
\hline \multicolumn{6}{|l|}{ Maternal age: } \\
\hline$<20$ & $575(3.0)$ & $415(3.5)$ & $774(2.3)$ & $1470(2.0)$ & $3234(2.4)$ \\
\hline $20-34$ & $16371(84.0)$ & $9989(84.4)$ & $28731(84.3)$ & $60486(84.3)$ & $115577(84.3)$ \\
\hline$\geqslant 35$ & $2534(13.0)$ & $1432(12.1)$ & $4558(13.4)$ & $9810(13.7)$ & $18334(13.4)$ \\
\hline \multicolumn{6}{|l|}{ Parity:^ } \\
\hline 0 & $7232(37.5)$ & $4164(35.6)$ & $13571(40.1)$ & $31033(43.5)$ & $56000(41.1)$ \\
\hline 1 & $6746(35.0)$ & $4076(34.8)$ & $12655(37.4)$ & $25456(35.7)$ & $48933(35.9)$ \\
\hline 2 & $3662(19.0)$ & $2467(21.1)$ & $5682(16.8)$ & $10846(15.2)$ & $22657(16.6)$ \\
\hline $3-$ & $1630(8.5)$ & $995(8.5)$ & $1921(5.7)$ & $4029(5.6)$ & $8575(6.3)$ \\
\hline \multicolumn{6}{|c|}{ Born in university clinic: } \\
\hline No & $19317(99.2)$ & $11146(94.2)$ & $32143(94.4)$ & $51711(72.1)$ & $114317(83.4)$ \\
\hline Yes & $163(0.8)$ & $690(5.8)$ & $1920(5.6)$ & $20055(27.9)$ & $22828(16.6)$ \\
\hline \multicolumn{6}{|l|}{ Centrality: } \\
\hline Low & $14734(75.6)$ & $7547(63.8)$ & $11386(33.4)$ & $11732(16.3)$ & $45399(33.1)$ \\
\hline Medium & $3922(20.1)$ & $958(8.1)$ & $10240(30.1)$ & $17497(24.4)$ & $32617(23.8)$ \\
\hline High & $824(4.2)$ & $3331(28.2)$ & $12437(36.5)$ & $42537(59.3)$ & $59129(43.1)$ \\
\hline \multicolumn{6}{|c|}{ Population density (urban/total population(\%)): } \\
\hline$<20$ & $2557(13.1)$ & $2193(18.5)$ & $682(2.0)$ & $1702(2.4)$ & $7134(5.2)$ \\
\hline $20-39.9$ & $3783(19.4)$ & $3249(27.5)$ & $1778(5.2)$ & $3911(5.4)$ & $12721(9.3)$ \\
\hline $40-59.9$ & $5456(28.0)$ & $2994(25.3)$ & $5923(17.4)$ & $5481(7.6)$ & $19854(14.5)$ \\
\hline $60-79.9$ & $6081(31.2)$ & $2359(19.9)$ & $7050(20.7)$ & $13869(19.3)$ & $29359(21.4)$ \\
\hline $80-$ & $1603(8.2)$ & $1041(8.8)$ & $18630(54.7)$ & $46803(65.2)$ & $68077(49.6)$ \\
\hline \multicolumn{6}{|c|}{ Industrial profile: } \\
\hline Low & $494(2.5)$ & $610(5.2)$ & $108(0.3)$ & $421(0.6)$ & $1633(1.2)$ \\
\hline Medium & $2025(10.4)$ & $985(8.3)$ & $2061(6.1)$ & $768(1.1)$ & $5839(4.3)$ \\
\hline High & $16961(87.1)$ & $10241(86.5)$ & $31894(93.6)$ & $70577(98.3)$ & $129673(94.6)$ \\
\hline
\end{tabular}

^Missing information 980 .

low birth weight $(<2500 \mathrm{~g})$, and small for gestational age. Small for gestational age was defined as birth weight equal to or less than the10th percentile, which was calculated from the present study population using 10 day intervals of gestational age. The preterm delivery was defined as gestational age less than 37 weeks.

\section{EXPOSURE ASSESSMENT}

Assessment of exposure was based on municipal water quality information on chlorination and natural organic matter content of raw water, and mothers' place of residence during pregnancy. A total of 233 waterworks in Norway, serving about 2.7 million people chlorinate their waters, and 1084 waterworks serving about 1.0 million people do not use chlorination. Exposure to chlorination byproducts through tap water takes place in areas where the waterworks chlorinate water with high levels of natural organic matter. Accordingly, we divided waterworks by the use of chlorination disinfection and used water colour in mg precipitate/l as a quantitative measure of the dissolved organic carbon. Water colour is highly correlated with the content of dissolved organic carbon $(r=0.82, \mathrm{n}=634) .{ }^{17}$ The colour number is recorded routinely in most of the waterworks. We calculated the weighted mean colour for each municipality with the fraction of population served by each waterwork as the weighting factor. We constructed four exposure categories on the basis of chlorination in the municipality (no or yes in one or more of the waterworks) and weighted mean colour (low $<10 \mathrm{mg}$ precipitate/1; high $\geqslant 10 \mathrm{mg}$ precipitate/ 1). Chlorination combined with high colour represented the hypothesised exposure to chlorination byproducts and no chlorination combined with low colour represented the reference category. The mean colour for waterworks that use surface water sources is $15 \mathrm{mg}$ precipitate $/ 1$ and $18 \%$ of the population served by such waterworks receive water with mean colour value below the cut off point of $10 \mathrm{mg}$ precipitate/l used in the analyses.

\section{COVARIATES}

Information on maternal age, parity, and the place of birth were obtained from the routine birth registry data. We received municipal data from the Norwegian social science data services, which were used to construct three covariates. "Centrality" indicates the municipality's urbanity and geographical placement relative to a regional centre. In the present analyses, we used this variable divided into three categories, low (municipalities with urban centres up to 15000 inhabitants), medium (urban areas up to 50000 inhabitants), and high (includes a regional centre). "Population density" is a measure of the proportion of urban population in the municipality. We used the following categories: $<20 \%$; $20 \%-39.9 \% ; 40 \%-59.9 \%, 60 \%-79.9 \%$ and $80 \%$ or more. "Industrial profile" describes the relative distribution of trades in the municipality.

\section{STATISTICAL METHODS}

We estimated the prevalence (\%) of the dichotomous reproductive outcomes with $95 \%$ confidence intervals (95\% CIs) based on the binomial distribution, and the mean of birth weight with $95 \%$ CIs based on the normal distribution. We compared the risks of adverse birth outcomes and mean birth weight between three exposure categories (chlorination and high colour; chlorination and low colour; no chlorination and high colour) and the reference category (no chlorination and low colour). We carried out bivariate analyses of the relations 
Table 2 Measures of birth weight and gestational age by population chlorination proportion, color, maternal age, parity, place of birth, centrality, population density and industrial profile in Norway 1993-95

\begin{tabular}{|c|c|c|c|c|c|}
\hline Determinant & $n$ & $\begin{array}{l}\text { Birth weight }(g) \\
\text { mean }(95 \% C I)\end{array}$ & $\begin{array}{l}\text { Low birth weight }(<2500 \mathrm{~g}) \\
\text { prevelence }(95 \% \mathrm{CI})\end{array}$ & $\begin{array}{l}\text { Small for gestational } \\
\text { age } \\
\text { prevelence }(95 \% \text { CI) }\end{array}$ & $\begin{array}{l}\text { Preterm delivery } \\
(<37 \text { weeks) } \\
\text { prevelence }(95 \% \text { CI) }\end{array}$ \\
\hline Total & 137145 & 3537 (3534 to 3540$)$ & & & \\
\hline \multicolumn{6}{|l|}{ Exposure category: } \\
\hline No chlorination, low colour & 19480 & 3544 (3535 to 3552$)$ & $4.5(4.24$ to 4.83$)$ & $4.5(4.18$ to 4.76$)$ & $6.7(6.37$ to 7.11$)$ \\
\hline No chlorination, high colour & 11836 & $3573(3562$ to 3584$)$ & $4.4(4.02$ to 4.75$)$ & $4.3(3.89$ to 4.61$)$ & $6.0(5.58$ to 6.50$)$ \\
\hline Chlorination, low colour & 34063 & 3546 (3540 to 3552$)$ & 4.5 (4.32 to 4.76$)$ & $4.5(4.24$ to 4.68$)$ & $6.4(6.17$ to 6.72$)$ \\
\hline Chlorination, high colour & 71766 & $3525(3521$ to 3530$)$ & $4.7(4.52$ to 4.83$)$ & $4.6(4.41$ to 4.72$)$ & $6.4(6.19$ to 6.56$)$ \\
\hline \multicolumn{6}{|l|}{ Maternal age: } \\
\hline$<20$ & 3234 & 3437 (3417 to 3458 ) & $5.8(5.00$ to 6.59$)$ & $5.7(4.86$ to 6.46$)$ & $8.8(7.70$ to 9.82$)$ \\
\hline $20-34$ & 115577 & 3540 (3536 to 3543 ) & $4.4(4.25$ to 4.49$)$ & $4.3(4.16$ to 4.39$)$ & $6.1(5.96$ to 6.25$)$ \\
\hline$\geqslant 35$ & 18334 & $3540(3530$ to 3549$)$ & $5.8(5.49$ to 6.16$)$ & 5.7 (5.39 to 6.06$)$ & $7.9(7.53$ to 8.35$)$ \\
\hline \multicolumn{6}{|l|}{ Parity* } \\
\hline 0 & 56000 & 3447 (3442 to 3452 ) & $5.8(5.64$ to 6.03$)$ & $5.7(5.52$ to 5.90$)$ & $7.5(7.24$ to 7.70$)$ \\
\hline 1 & 48933 & $3590(3585$ to 3596$)$ & $3.6(3.40$ to 3.73$)$ & $3.5(3.34$ to 3.66$)$ & $5.4(5.20$ to 5.61$)$ \\
\hline 2 & 22657 & $3622(3614$ to 3630$)$ & 3.7 (3.44 to 3.94$)$ & $3.6(3.35$ to 3.84$)$ & $5.8(5.47$ to 6.11$)$ \\
\hline$\geqslant 3$ & 8575 & $3600(3586$ to 3614$)$ & $4.7(4.22$ to 5.11$)$ & $4.6(4.15$ to 5.04$)$ & $7.0(6.37$ to 7.51$)$ \\
\hline \multicolumn{6}{|l|}{ Born in university clinic: } \\
\hline No & 114317 & 3546 (3543 to 3550$)$ & $4.5(4.33$ to 4.57$)$ & $4.4(4.24$ to 4.48$)$ & $6.3(6.15$ to 6.44$)$ \\
\hline Yes & 22828 & 3492 (3484 to 3500$)$ & $5.3(5.03$ to 5.61$)$ & $5.2(4.90$ to 5.47$)$ & $7.0(6.66$ to 7.35$)$ \\
\hline \multicolumn{6}{|l|}{ Centrality: } \\
\hline Low & 45399 & 3548 (3543 to 3554$)$ & $4.4(4.26$ to 4.64$)$ & $4.4(4.17$ to 4.55$)$ & $6.4(6.14$ to 6.62$)$ \\
\hline Medium & 32617 & 3539 (3533 to 3546$)$ & $4.7(4.50$ to 4.96$)$ & $4.6(4.41$ to 4.86$)$ & $6.4(6.16$ to 6.73$)$ \\
\hline High & 59129 & $3528(3523$ to 3532$)$ & $4.6(4.46$ to 4.80$)$ & $4.5(4.36$ to 4.70$)$ & $6.4(6.22$ to 6.63$)$ \\
\hline \multicolumn{6}{|c|}{ Population density (urban/total population (\%)): } \\
\hline$<20$ & 7134 & 3567 (3552 to 3581$)$ & 4.5 (4.01 to 5.00$)$ & $4.4(3.93$ to 4.88$)$ & $6.6(5.94$ to 7.16$)$ \\
\hline 20-39.9 & 12721 & 3571 (3561 to 3582$)$ & 4.1 (3.77 to 4.47$)$ & $4.1(3.73$ to 4.42$)$ & $5.7(5.26$ to 6.11$)$ \\
\hline $40-59.9$ & 19854 & 3557 (3548 to 3565$)$ & $4.4(4.11$ to 4.68$)$ & $4.3(4.01$ to 4.58$)$ & $6.6(6.23$ to 6.96$)$ \\
\hline $60-79.9$ & 29359 & 3540 (3532 to 3546$)$ & $4.7(4.41$ to 4.89$)$ & $4.6(4.32$ to 4.80$)$ & $6.4(6.12$ to 6.72$)$ \\
\hline$\geqslant 80$ & 68077 & 3521 (3517 to 3526$)$ & 4.7 (4.57 to 4.89$)$ & $4.6(4.46$ to 4.78$)$ & $6.5(6.29$ to 6.68$)$ \\
\hline \multicolumn{6}{|l|}{ Industrial profile: } \\
\hline Low & 1633 & 3565 (3536 to 3594$)$ & $4.0(3.03$ to 4.93$)$ & $3.8(2.87$ to 4.73$)$ & $7.5(6.21$ to 8.89$)$ \\
\hline Medium & 5839 & 3552 (3536 to 3568$)$ & $4.4(3.88$ to 4.93$)$ & $4.3(3.80$ to 4.80$)$ & $6.1(5.42$ to 6.71$)$ \\
\hline High & 129673 & $3536(3533$ to 3540$)$ & 4.6 (4.50 to 4.73$)$ & 4.5 (4.40 to 4.63$)$ & $6.4(6.28$ to 6.56$)$ \\
\hline
\end{tabular}

${ }^{\star}$ Missing information 980 .

between the outcomes and exposures of interest. We used logistic regression to estimate adjusted odds ratios (ORs) for dichotomous outcomes, and linear regression to estimate the relations between exposure and birth weight. We included in the model all the potential determinants of the outcomes including maternal characteristics such as age and parity, the child's place of birth in the three university clinics located in the three largest cities in Norway (yes or no), and municipal indicators of socioeconomic level-such as centrality, population density, and industrial profile - of the municipality where the mother lived during pregnancy. To elaborate residual confounding, we studied the impact of each covariate by comparing measures of effect from models with and without the covariate of interest. We fitted models with different combinations of covariates. We also compared the measures of effect within different categories to show residual confounding and to elaborate effect modification. In the results section, we present systematically the risk estimates from the full model, because they provide the most valid or least confounded estimates.

\section{Results}

COMPARISON OF EXPOSED AND UNEXPOSED

Table 1 shows the study population according to the exposure categories. The municipalities with chlorination and high colour were more central, had a higher population density, and a larger proportion of mothers using the three university clinics compared with the reference category. The mean birth weight and the prevalence for low birth weight, small for gestational age, and preterm delivery are presented in the main categories of water quality and covariates in table 2 .

LOW BIRTH WEIGHT

Among the total of 137145 newborn infants, we identified $6249(4.6 \%)$ with birth weight below $2500 \mathrm{~g}$. Table 2 shows the mean birth weight and the prevalence of the other outcomes by exposure and the other covariates. The mean birth weight in the chlorination and high colour exposure category (3525 g) was slightly lower than in the reference category (3544 g). We estimated the effect of exposure to chlorinated humic water on birth weight in linear regression analysis controlling for maternal age, parity, place of birth, centrality, industrial profile, and population density. The birth weight in the chlorination and high colour category was estimated as $4 \mathrm{~g}$ (95\% CI -7.7 to 14.6) greater than in the reference category. The corresponding differences were $20 \mathrm{~g}$ (95\% CI 6.2 to 34.2) for the no chlorination and high colour category, and $12 \mathrm{~g}$ (95\% CI 0.3 to 33.3) for the chlorination and low colour category.

The adjusted OR of low birth weight contrasting chlorination and high colour with the reference category was 0.97 (0.89 to 1.06). The risk of low birth weight was related to neither the high chlorination nor high colour alone (table 3).

SMALL FOR GESTATIONAL AGE

Both birth weight and gestational age, needed for the calculation of being small for gestational age, were available for 123747 newborn infants. As shown in table 3, the risk of small for gestational age was not related to exposure to chlorinated humic water (adjusted OR 1.00, $95 \%$ CI 0.91 to 1.10 ), unchlorinated water 
Table 3 Water chlorination and risk of adverse reproductive outcomes in Norway 1993-5

\begin{tabular}{|c|c|c|c|}
\hline Exposure category & $\begin{array}{l}\text { Low birth weight } \\
(<2500 \mathrm{~g}) \\
n=137145 \\
O R^{\star}(95 \% \mathrm{CI})\end{array}$ & $\begin{array}{l}\text { Small for gestational } \\
\text { age } \\
n=123747 \\
O R^{\star}(95 \% \text { CI })\end{array}$ & $\begin{array}{l}\text { Preterm delivery } \\
(<37 \text { weeks }) \\
n=123747 \\
O R^{\star}(95 \% \mathrm{CI})\end{array}$ \\
\hline & & & \\
\hline No chlorination, high colour & $1.02(0.91$ to 1.1 & $1.02(0.89$ to 1.14$)$ & $0.92(0.83$ to 1.03$)$ \\
\hline Chlorination, low colour & $0.99(0.90$ to 1.09$)$ & $1.00(0.91$ to 1.11$)$ & $0.95(0.88$ to 1.03$)$ \\
\hline Chlorination, high colour & $0.97(0.89$ to 1.06$)$ & $1.00(0.91$ to 1.10$)$ & $0.91(0.84$ to 0.99$)$ \\
\hline
\end{tabular}

^Logistic regression analysis adjusting for maternal age and parity, the child's place of birth, centrality, population density, and industrial profile of the municipality where the mother lived during pregnancy.

with high colour (OR 1.02, 95\% CI 0.89 to $1.14)$ or chlorinated water with low colour (OR $1.00,95 \%$ CI 0.91 to 1.11 ).

PRETERM DELIVERY

There were $7886(6.4 \%)$ preterm deliveries in the study population. In the logistic regression models, we found no increase in the risk of preterm delivery related to exposure to chlorinated high colour tap water (table 3). Contrary to our hypothesis, the risk of preterm delivery was lower among the exposed population than in the reference category (adjusted OR 0.91, $95 \%$ CI 0.84 to 0.99 ). The risks were slightly reduced also in no chlorination high colour (OR $0.92,95 \%$ CI 0.83 to 1.03 ) and chlorination, low colour categories (OR 0.95, 95\% CI 0.88 to 1.03 ), although upper confidence limits were above unity.

\section{Discussion}

In this Norwegian study, we found no association between foetal growth and exposure to chlorinated surface water containing natural organic matter during pregnancy. The risk of preterm delivery was slightly lower in the exposed than in the reference group, which was contrary to our initial hypothesis.

VALIDITY OF RESULTS

Definition of relevant disinfection byproducts and assessment of exposure to these compounds represents a challenge for studies on effects on health, as recently discussed by Swan and Waller. ${ }^{18}$ Exposure to chlorinated water containing natural organic matter may result in complex mixtures with many potential causes of adverse reproductive effects. Exposure to a single component may be a contributor to adverse pregnancy outcomes, but at the same time it is likely to be an indicator of exposure to several other causal agents. A substantial variation in concentrations of byproducts over time adds another dimension of complexity.

Five of the six previous studies based their exposure assessment on measured concentrations of trihalomethane in municipal water and maternal residential address. ${ }^{58101114}$ Also, Gallagher et $a l^{10}$ applied hydraulic modelling and Dodds et $a l^{11}$ modelled information from three sources to estimate residential specific concentrations. Savitz et al incorporated information on consumption of tap water during pregnancy to improve the individual exposure estimates.

We were not able to use concentrations of trihalomethane, which limits the comparability of the present and previous results. Although total trihalomethanes are commonly used in monitoring disinfection byproducts, they may not be the main causes of the studied outcomes. Animal toxicological studies suggest that several different disinfection byproducts may cause reproductive effects including dichloroacetic acid, ${ }^{19}$ trichloroacetic acid, ${ }^{20}$ dichloroacetonitrile, ${ }^{21}$ and trichloroacetonitrile. ${ }^{2022}$ With total trihalomethanes as an indicator of exposure, it is difficult to separate the effects of chlorination byproducts from the effects of organic substances with higher molecular weight, because concentrations of organic compounds, some of which serve as precursors of chlorination byproducts, are likely to be related to concentrations of total trihalomethanes. Presence of natural organic matter may also be related to other chemical compounds with teratogenic effects, such as methylmercury and polychlorinated biplenyls. Control of this potential confounding would require information on many different chemicals. The concentrations of these potential confounders may vary according to geographic region and time. Assessment of time specific and individual exposure would not resolve this problem. A more feasible solution would be a study design, in which a comparison is made between exposure to chlorinated surface water and similar (preferably identical) unchlorinated surface waters. Unlike previous study areas in the United States and Canada, Norwegian waterworks commonly distribute unchlorinated surface water with a relatively high content of natural organic matter and at the same time some municipalities chlorinate source water with a low content of organic matter. This unusual setting made it possible to assess the effect of organic matter independent from the effect of chlorination as well as to assess the effect of chlorination in waters with both high and low content of organic matter.

We had no information on the individual amounts or sources of water consumed by women, which decreased the accuracy of exposure assessment. Alcohol consumption and cigarette smoking, particularly after the 28th week of gestation, are well established causes of reduction in foetal growth. We were not able to take into account these important determinants of reproductive outcomes. However, we do not have any reason to think that on an individual level chlorination and natural organic matter were associated with either smoking or drinking. Adjustment for centrality, population density, and industrial profile adjusted indirectly for regional differences in these behavioural factors. Registry linkage provided information on several potential municipal confounders, which were taken into account in the data analysis.

SYNTHESIS WITH PREVIOUS KNOWLEDGE

The observed lower risk of preterm delivery in the exposed groups was contrary to our original hypothesis. A possible explanation for this finding is that residual chlorine in chlorinated water lowers the risk of preterm delivery by preventing maternal infections during pregnancy. However, the five previous studies 


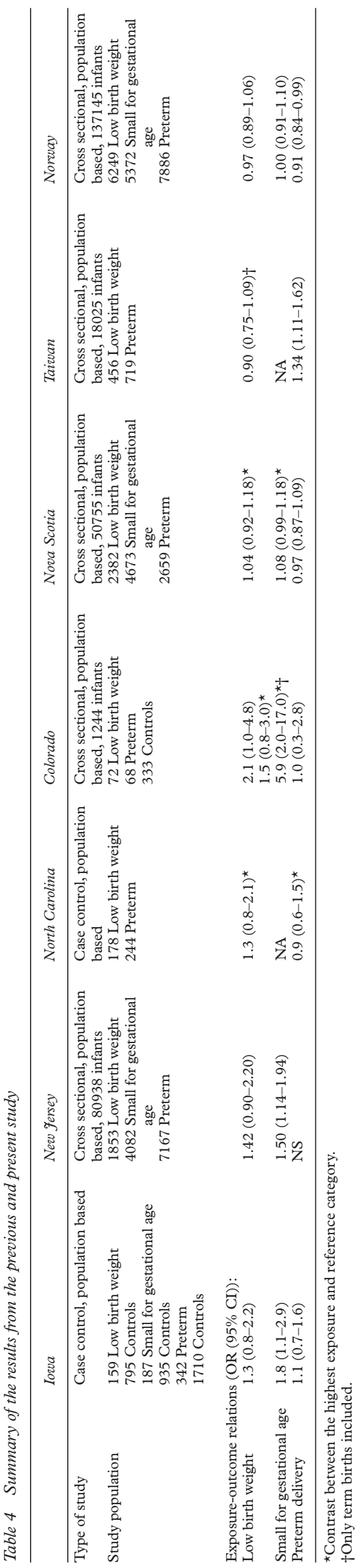

provided inconsistent results (table 4). Studies from Iowa, ${ }^{5}$ North Carolina, ${ }^{8}$ Colorado, ${ }^{10}$ and Nova Scotia ${ }^{11}$ reported risk estimates close to unity. The most recent study, from Taiwan, reported an increased risk (OR (95\% CI) 1.31 (1.11 to 1.62$)$ ) related to maternal place of residence in a community with chlorinated drinking water. $^{14}$ The present evidence is controversial and therefore epidemiological studies should elaborate further the relation between exposure to chlorination byproducts and duration of gestation.

The present study indicated no effect of chlorination byproducts on foetal growth, on the risk of low birth weight, or being small for gestational age. The previous risk estimates for low birth weight are heterogeneous, as shown in table 4. Population based case-control studies from Iowa ${ }^{5}$ and North Carolina ${ }^{8}$ and the two cross sectional studies from New Jersey ${ }^{7}$ and Colorado ${ }^{10}$ reported an increased risk, whereas the risk estimate from a study conducted in Taiwan ${ }^{14}$ indicated a decreased risk. All the four previous studies on gestational age reported increased ORs varying from 1.08 to 5.9 .

The inconsistency of the findings could be related to both qualitative and quantitative differences in exposure between the compared studies. Although chlorination was the common method of disinfection, the proportion of individual chlorination byproducts may vary between the geographic regions due to differences in the raw water quality including the character of the organic compounds in the source water, which are important precursors of the chlorination byproducts. In the Iowa study, concentrations of four trihalomethaneschloroform, bromodichloromethane, dibromochloromethane, and bromoform-from a municipal water quality survey were used as measures of exposure. ${ }^{5}$ Intrauterine growth retardation was related to chloroform concentrations above $10 \mu \mathrm{g} / 1$. The relation was consistent both in shallow and deep sources of water, which was thought to argue against confounding due to pesticides or other contaminants known to vary by the depth of the water source. In the New Jersey, Colorado, and Nova Scotia studies concentrations of total trihalomethane were used as a measure of exposure and the effects of rather similar exposures were inconsistent. This points towards qualitative differences in the complex mixture. A study of 21 waterworks thet use chlorination describes the levels of exposure in Norway. ${ }^{23}$ The mean concentration of total trihalomethanes was $9.4 \mu \mathrm{g} / 1$ and the mean for halogenated acetic acids was $14.6 \mu \mathrm{g} / \mathrm{l}$, clearly lower than concentrations reported in the United States. ${ }^{5-10} 18$ and Canadian ${ }^{11}$ drinking water sources, although the average colour was $22 \mathrm{mg}$ precipitate/ 1 for these selected Norwegian waterworks.

\section{Conclusion}

In summary, our study indicates that the present practices of chlorination of Norwegian surface waters does not increase the risk of low birth weight, small for gestational age, or preterm delivery. The current body of evidence 
including the present and five previous studies indicates little effect on the risk of preterm delivery. The studies of foetal growth are inconsistent, probably partly due to qualitative geographic differences in natural organic matter and lower concentrations of chlorination byproducts in Norwegian drinking waters compared with the United States and Canadian drinking waters.

This study was supported by the Norwegian Research Council.

1 Rook JJ. Formation of haloforms during chlorination of natural waters. Water Treatment Examinations 1974;23:902 .

International Agency for Research on Cancer. Chlorinated drinking water; chlorination by-products; some other halogenated compounds, cobalt and cobalt compounds. IARC Monogr Eval Carcinog Risks Hum 1991;52:45-337.

Morris RD, Audet AM, Angelillo IF, et al. Chlorination, chlorination by-products and cancer: a meta-analysis. Am $\mathcal{F}$ Public Health 1992;82:955-63.

4 Koivusalo M, Hakulinen T, Vartiainen T, et al. Drinking water mutagenicity and urinary tract cancers: a populationbased case-control study in Finland. Am $\mathcal{F}$ Epidemiol 1998; 148:704-12.

5 Kramer MD, Lynch CF, Isacson P, et al. The association of waterborne chloroform with intrauterine growth retardation. Epidemiology 1992;3:407-13.

6 Aschengrau A, Zierler S, Cohen A. Quality of community drinking water and the occurrence of late adverse pregnancy outcomes. Arch Environ Health 1993;48:10513 .

7 Bove FJ, Fulcomer MC, Klotz JB, et al. Public drinking water contamination and birth outcome. Am 7 Epidemiol 1995;141:850-62

8 Savitz DA, Andrews KW, Pastore LM. Drinking water and pregnancy outcome in central North Carolina: source, amount, trihalomethane levels. Environ Health Perspect 1995;103:592-6.
9 Waller K, Swan SH, DeLorenze G, et al. Trihalomethanes in drinking water and spontaneous abortion. Epidemiology 1998;9:134-40

10 Gallagher MD, Nuckols JR, Stallones L, et al. Exposure to trihalomethanes and adverse pregnancy outcomes. Epidemiology 1998;9:484-9.

11 Dodds L, King W, Woolcott C, et al. Trihalomethanes in public water supplies and adverse birth outcomes. Epidemiology 1999;10:233-7.

12 Klotz JB, Pyrch LA. Neural tube defects and drinking water disinfection by-products. Epidemiology 1999;10:383-90.

13 Magnus P, Jaakkola JJK, Skrondal A, et al. Water chlorination and birth defects. Epidemiology 1999;10:51317.

14 Yang CY, Cheng BH, Tsai SS, et al. Association between chlorination of drinking water and adverse pregnancy outcome in Taiwan. Environ Health Perspect 2000;108:765-8.

15 Nieuwenhuijsen MJ, Toledano MB, Eaton NE, et al. Chlorination disinfection byproducts in water and their association with adverse reproductive outcomes: a review. Occup Environ Med 2000;57:73-85.

16 Births in Norway through 30 years. Bergen; Medical Birth Registry of Norway, 1998. (In Norwegian.)

17 Hongve D, Andersen T. Factors determining the light absorption of aquatic humic substances. Finnish Humus News 1991;3:209-14.

18 Swan SH, Waller K. Disinfection by-products and adverse pregnancy outcomes: what is the agent and how should it be measured. Epidemiology 1998;9:479-81.

19 Smith MK, Randall JL, Read JL, et al. Developmental toxicity of dichloroacetate in the rat. Teratology 1992;46:217-23.

20 Smith MK, Randall JL, Stober JA. Teratogenic activity of trichloroacetic acid in the rat. Teratology 1989;40:445-51.

21 Smith MK, George EL, Zenick H, et al. Developmental toxicity of halogenated acetonitriles: drinking water byproducts of chlorine disinfection. Toxicology 1987;46:8393.

22 Smith MK, Randall JL, Tocco DR, et al. Teratogenic effects of trichloroacetonitrile in the Long-Evans rat. Teratology 1988;33:113-20.

23 Aune K, Becher G, Froshaug M, et al. Chlorination by-products in selected Norwegian drinking waters. Presented at the 8th Meeting of the International Humic Substances Society. Wroclaw, Poland: IHSS, 1996.

\section{Vancouver style}

All manuscripts submitted to Occup Environ Med should conform to the uniform requirements for manuscripts submitted to biomedical journals (known as the Vancouver style.)

Occup Environ Med, together with many other international biomedical journals, has agreed to accept articles prepared in accordance with the Vancouver style. The style (described in full in the $\mathcal{F} A M A[1]$ ) is intended to standardise requirements for authors, and is the same as in this issue.

References should be numbered consecutively in the order in which they are first mentioned in the text by Arabic numerals on the line in square brackets on each occasion the reference is cited (Manson[1] confirmed other reports[2][3][4][5]). In future references to papers submitted to Occup Environ Med should include: the names of all authors if there are three or less or, if there are more, the first three followed by et al; the title of journal articles or book chapters; the titles of journals abbreviated according to the style of Index Medicus; and the first and final page numbers of the article or chapter. Titles not in Index Medicus should be given in full.

Examples of common forms of references are:

1 International Committee of Medical Journal Editors. Uniform requirements for manuscripts submitted to biomed journals. $\mathscr{F} A M A$ 1993;269:2282-6.

2 Soter NA, Wasserman SI, Austen KF. Cold urticaria: release into the circulation of histmaine and eosinophil chemotactic factor of anaphylaxis during cold challenge. N Engl F Med 1976;294:687-90.

3 Weinstein L, Swartz MN. Pathogenic properties of invading micro-organisms. In: Sodeman WA Jr, Sodeman WA, eds. Pathologic physiology, mechanisms of disease. Philadelphia: W B Saunders, 1974:457-72. 